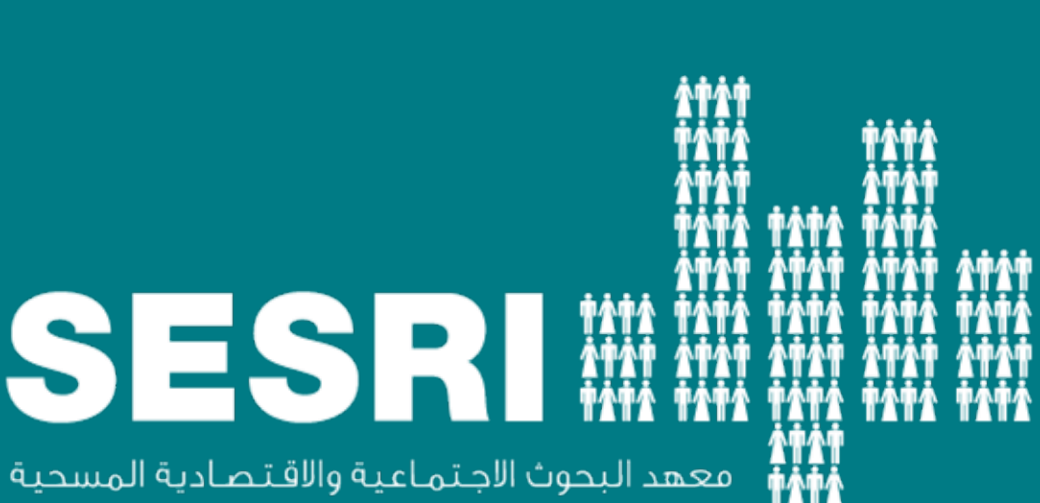
Faculty, Humanities and Social Sciences

\section{Qatar's labor law changes and worker's welfare:}

\section{Attitudes and perceptions for a sustainable future}

Abdoulaye Diop (LPI), Kien T. Le, Buthaina Al Khelaifi,

Engi El-Maghraby, Haneen Alqassass, Lina Bader, Šemsia Al-Ali Mustafa

Social and Economic Survey Research Institute (SESRI)

\section{Introduction}

- This 11th cycle NPRP (11S-1205-170065) project is a comprehensive survey project that assesses changes and continuity in perceptions and attitudes about Qatar's Labour Law among Qatari nationals, high-income and low-income expatriate workers.*

- Additionally, Qatari \& expatriate businessmen are screened and asked specific questions about the impact of the reforms on their businesses, recruitment and hiring practices as well as entrepreneurial aspirations.

\section{Objective}

The research's main objective is related to Qatar's efforts to develop local manpower resources in support of its burgeoning knowledgebased economy. The project aims to provide a conceptual map to face the continued challenges of employing expatriate labor and attenuate any associated problems.

The research agenda for this project is:

- To have better understanding of what underlying factors drive citizens' and residents' perceptions of the new system for recruiting and employing foreign workers.

- To provide policymakers with feedback and information from major stakeholders that would allow them to fine-tune \& calibrate labour policies for a sustainable future.

\section{Methodology}

- The sample consisted of 2,760 respondents, of whom 857 were Qatari nationals, 1,012 high-income expatriates and 891 lowincome expatriates. **

- Due to Covid-19 pandemic, the survey was conducted via telephone interviewing (CATI) from September 22, 2020 to

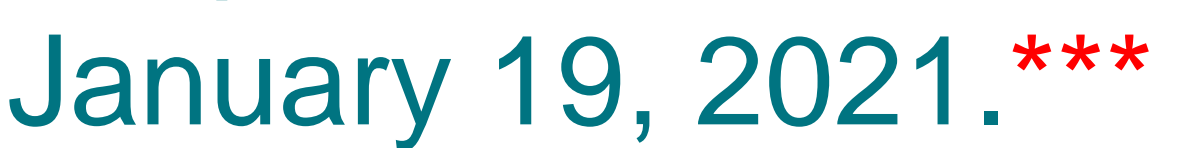

- The interviews were conducted in Arabic, English, Tagalog, Urdu, Bengali, Nepali, Malayalam, Tamil and Hindi.

- Respondents were asked questions about their attitudes and perceptions of Qataris and expatriate workers on the recent Qatar Labor Law changes.

* The findings herein was made possible by NPRP grant \# [11S1205-170065] from the Qatar National Research Fund (a member of Qatar Foundation). The findings herein reflect the work, and are solely the responsibility, of the authors.

** Response rate (43.4\%), Sampling error ( \pm 2.5 percentage points) *** QU-IRB 1012-A/19

\begin{tabular}{|c|c|c|c|c|}
\hline \multicolumn{5}{|l|}{ Awareness } \\
\hline $\begin{array}{l}\text { Since 2016, Qatar has been } \\
\text { introducing changes to the Labor } \\
\text { Law. How familiar are you with the } \\
\text { new labor law changes? }\end{array}$ & Whole sample & Qataris & $\begin{array}{l}\text { Higher-income } \\
\text { expats }\end{array}$ & $\begin{array}{l}\text { Lower-income } \\
\text { expats }\end{array}$ \\
\hline Very familiar & $9 \%$ & $9 \%$ & $12 \%$ & $7 \%$ \\
\hline Somewhat familiar & $60 \%$ & $48 \%$ & $61 \%$ & $61 \%$ \\
\hline Not at all familiar & $31 \%$ & $43 \%$ & $27 \%$ & $32 \%$ \\
\hline \multicolumn{5}{|l|}{ Minimum wage } \\
\hline $\begin{array}{l}\text { Should the minimum wage be increased, } \\
\text { maintained at } 1000 \text { QAR or decreased? }\end{array}$ & Qataris & \multicolumn{2}{|c|}{ Higher-income expats Low } & er-income expats \\
\hline Increased & $34 \%$ & \multicolumn{2}{|c|}{$78 \%$} & $77 \%$ \\
\hline Maintained at 1000 QAR & $58 \%$ & \multicolumn{2}{|c|}{$21 \%$} & $23 \%$ \\
\hline Decreased & $8 \%$ & \multicolumn{2}{|c|}{$1 \%$} & $0 \%$ \\
\hline
\end{tabular}

\section{Impact}

\begin{tabular}{lccc}
\hline $\begin{array}{l}\text { In the future, do you } \\
\text { think these new Labor } \\
\text { Law changes will make } \\
\text { your life? }\end{array}$ & Qataris & $\begin{array}{c}\text { Higher- } \\
\text { income expats }\end{array}$ & $\begin{array}{c}\text { Lower-incom } \\
\text { expats }\end{array}$ \\
Much better & $\mathbf{3 8 \%}$ & $\mathbf{5 2 \%}$ & $\mathbf{5 0 \%}$ \\
Somewhat better & $\mathbf{2 7 \%}$ & $\mathbf{3 3 \%}$ & $\mathbf{4 2 \%}$ \\
Somewhat worse & $12 \%$ & $2 \%$ & $1 \%$ \\
Much worse & $6 \%$ & $1 \%$ & $0 \%$ \\
Made no difference & $17 \%$ & $12 \%$ & $\mathbf{7 \%}$ \\
\hline
\end{tabular}

Has your business been positively or negatively affected by the recent changes in the Qatar Labor Law

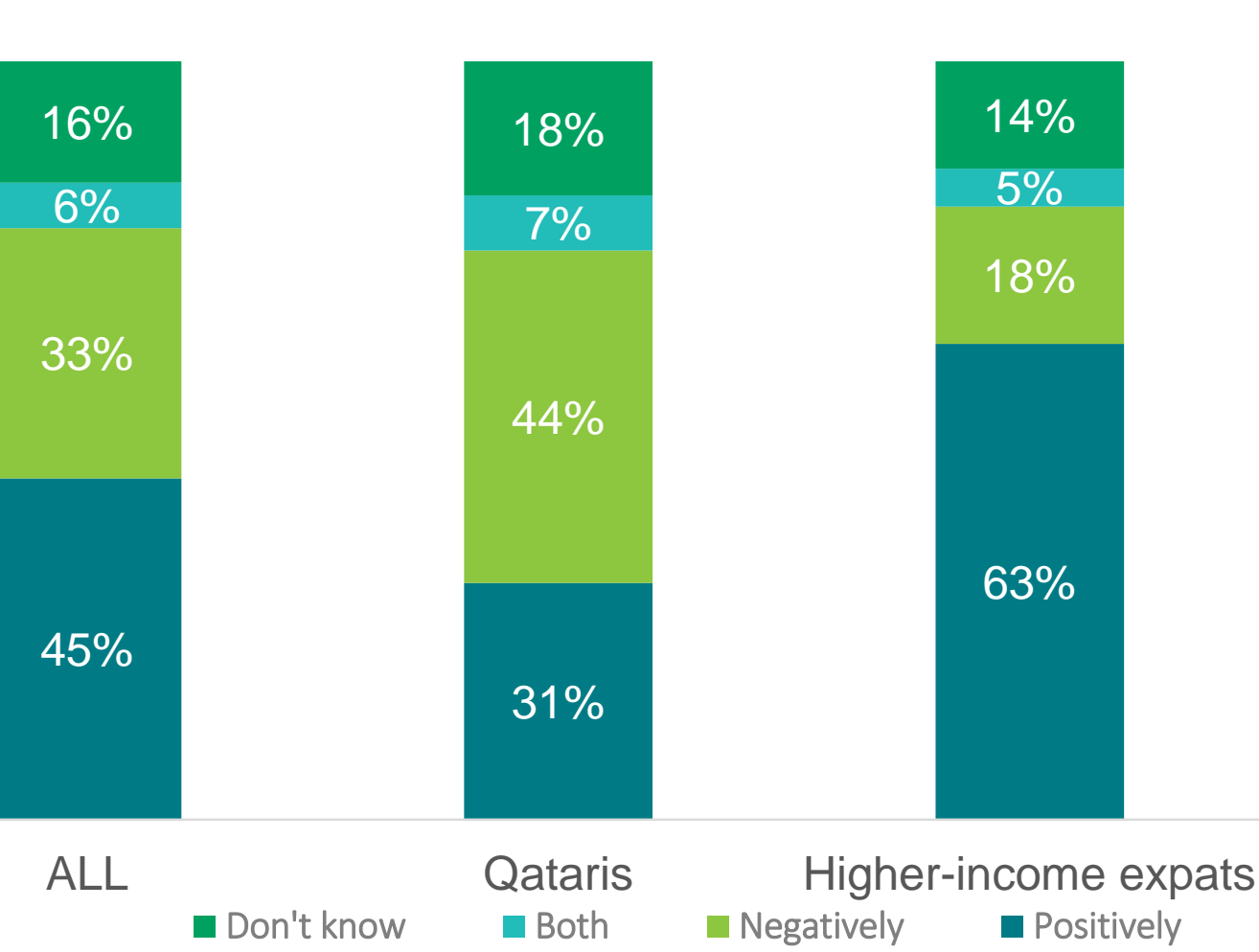

\title{
Inspection of businesses
}

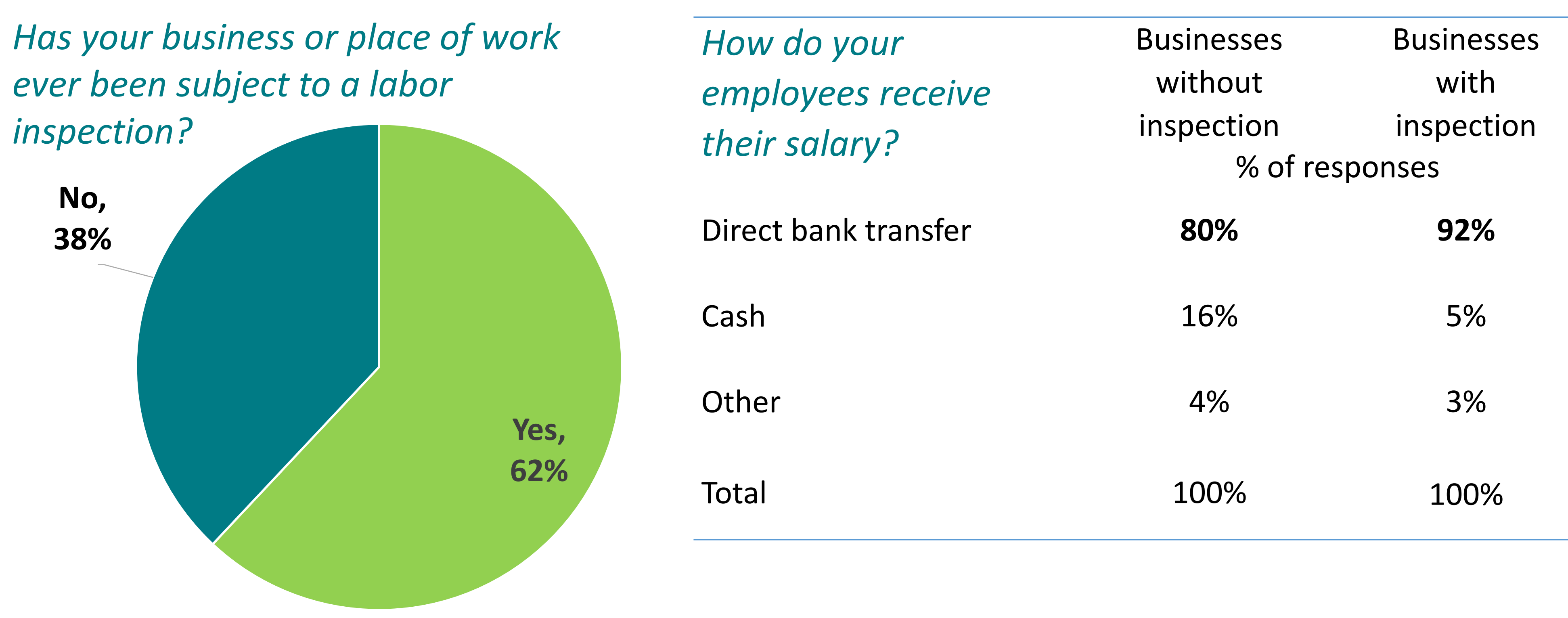

\section{Recommendations}

- Awareness campaigns about the reforms for Qatari nationals, expatriates (high \& low-income) due to low levels of awareness.

- Increase inspections across businesses for effective implementation of reforms as inspection pushes businesses to abide by the reforms.

- Follow-up study on the impact of the minimum wage, businesses

hiring practices, and impact of the reforms. 